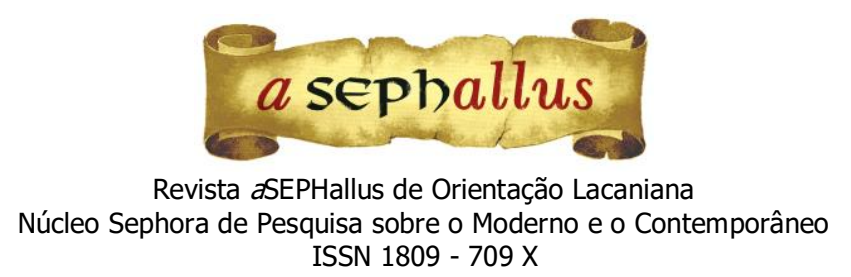

ISSN $1809-709 \mathrm{X}$

\title{
A Sociedade não existe!
}

Erly Alexandrino da Silva Neto

Psicanalista

Associado ao ISEPOL

Psicólogo pela UFES

Especialista em Psicanálise pelo EAP/FAFIA

Mestre em Teoria Psicanalítica pelo PPGTP/UFRJ

Doutorando em Teoria Psicanalítica pelo PPGTP/UFRJ

E-mail: erlyneto@gmail.com

\section{Resenha do livro}

Žižek, Slavoj. (2016). O sujeito incômodo: o centro ausente da ontologia política. São Paulo: Boi Tempo.

O século XXI não é para principiantes!

As reviravoltas políticas no cenário internacional, com o crescimento galopante das forças conservadoras sob a forma de um neonacionalismo xenófobo, antiglobalização - vide a vitória de Donald Trump nos Estados Unidos, o crescimento das intenções de voto em Le Pen na França e a legião de seguidores que Bolsonaro cativa -, pegou de surpresa não apenas os adeptos do multiculturalismo liberal e apoiadores militantes das políticas afirmativas para minorias - ou seja, a esquerda light - como, também, uma direita importante ligada ao capitalismo financeiro global: não faltaram periódicos de economia nacionais e internacionais (ex.: The Economist e InfoMoney) a usar o termo 'iliberal' para descrever esta mentalidade política em crescimento.

Também nos deixou atônitos a eficácia revigorada da retórica política do populismo, seja ele à esquerda ou à direita, em um descompromisso tão grande com os fatos, dados e coerência interna que renderam ao termo "pós-verdade" o título de palavra do ano pela Oxford, a editora dos famosos dicionários.

Boa parte desse avanço inesperado de uma direita antiglobalista e segregacionista deveuse a outra surpresa acachapante: os governos de esquerda ou centro-esquerda vitoriosos das eleições do final do século XX e início do XXI saem derrotados moralmente por mostrarem-se adeptos das mesmas práticas criminosas de grupos tradicionais da política nacional e global.

Neste cenário de fracasso das coalizões sociais-democratas, com a subsequente radicalização dos discursos da esquerda e da direita, fica claro que testemunhamos uma reedição de posições políticas que são datadas, anacrônicas, para as quais recorre-se às pressas de modo a se entrincheirar nas fileiras da disputa pelo poder ou por um lugar ao sol.

Em meio a esse cenário vertiginoso e surpreendente, onde tantos se apressam à ação impensada, Žižek, invertendo a máxima de Marx, propõe que "já mudamos o mundo o bastante, agora é hora de o pensarmos". 
Em O sujeito incômodo (Žižek, 2016), o autor parte de categorias universalistas kantianas e do sujeito hegeliano incômodo, coloca-as à luz da psicanálise lacaniana e aborda com uma propriedade sem igual o ponto mais agudo deste cenário político, qual seja, a sensação vertiginosa de que nosso assoalho social, o conjunto de crenças coletivas que mantém nossa sociedade funcionando está desmoronando ou já desmoronou. Pois bem, para ele é justamente isso!

Estamos sim diante de uma grave crise da noção hegemônica de universalidade, mas essa é a própria estrutura dessa noção. Para Žižek, as categorias como justiça, honestidade, verdade, eficiência, etc., são categorias vazias, sem nenhuma substância própria na esfera universal. Elas só podem assumir um valor substancial em experiências muito singulares. A montagem de uma noção universal de justiça, portanto, será apoiada por determinados casos particulares elevados à categoria de universais, o universe/ singulier, uma espécie de curto-circuito na construção da categoria de maneira que ela não é verdadeiramente universal, pois exclui, de forma passiva, outras representações singulares de justiça que não estejam presentes no caso singular escolhido para constituí-la.

Em uma aproximação muito bem feita com a teoria lacaniana, o autor aproxima esse curtocircuito à construção das categorias universais através de materiais particulares à noção psicanalista de fantasia inconsciente: a categoria universal vazia seria equivalente ao desejo, sempre em falta, tamponado com uma fantasia inconsciente construída ao redor de um objeto real, mas que se constitui apenas na singularidade das fantasias de satisfação de um sujeito. Este objeto, portanto, jamais poderia estar à altura de satisfazer o desejo puro, que é sempre desejo de outra coisa.

O próprio desejo de outra coisa, tributário da pulsão de morte - destruir para começar com novos custos, segundo a fórmula de Lacan em seu seminário sobre a Ética da psicanálise (Lacan, 1959-1960/1997) - é comparado às incessantes demandas dos que se identificam à não-parte do stablishment político e que o forçam a se reconstruir em um novo ato fundador. A política, portanto, é equiparada à noção freudiana de conflito psíquico, sendo compreendida como o terreno de conflito entre diversos atores, diversas classes.

A noção marxista de luta de classes é retomada, mas atualizada pela noção freudiana de psiquismo como conflito. Classe não é uma categoria estanque da bem delimitada sociedade, não há uma "classe dos trabalhadores" ou "classe dos proprietários" de maneira bem definida e autoconsciente. A própria delimitação das classes e suas autoconsciências são borradas, movediças e altamente influenciadas pelas ideologias. A exemplo disso, Slavoj nos mostra a classe média como uma categoria de não-classe por excelência, pois ao rechaçar os extremos das posições políticas em favor de suas posições éticas, morais e religiosas, define-se pela negação do que é uma classe.

Mesmo a noção de ideologia é revista com contribuições psicanalíticas, pois longe de ser algo falso que a classe dominante utiliza para alienar a classe trabalhadora, uma ideologia é entendida aqui como equivalente ao fantasma lacaniano, ou seja, uma estrutura simbólica inconsciente - um enredo, uma cena - que organiza uma certa forma de funcionamento da máquina 
de satisfação do sujeito, no caso, o modo de uma sociedade funcionar. Não há, portanto, uma verdade camuflada, escamoteada pela ideologia. Ela é uma ficção com efeitos de verdade. Ou seja, o que se pode fazer é trocar uma ideologia por outra; para além disso há apenas a constatação de que "A sociedade não existe" (em mais um paralelo à teoria psicanalítica lacaniana que, em um dado momento, parte do axioma "a relação sexual não existe").

A partir deste ponto de vista, Žižek constrói uma poderosa crítica tanto às direitas - liberal e ultraconservadora - quanto às esquerdas - do multiculturalismo liberal, da ultracrítica ou da revolucionária - definindo-as como defesas à política de fato.

No caso das esquerdas, a crítica ao multiculturalismo liberal se dá no nível da negação da política - do conflito - que a tentativa liberal engendra ao criar categorias inclusivas para todos em sua organização social, de uma maneira estanque, na tentativa de pacificar conflitos. A consequência dessa posição é a eclosão dos atos de ódio - racismo, assassinatos de gays, xenofobia, etc. A vertente mais à esquerda das políticas afirmativas é equiparada, formalmente, à estrutura dos movimentos fundamentalistas de direita que retomam as identidades perdidas no processo de globalização das nações. Ou seja, entre um militante das minorias e um evangélico ultraconservador o fundamentalismo está nos olhos de quem vê.

No da esquerda ultracrítica, ela estaria ainda mais adequada à ordem do capital, pois ao esperarem pela revolução pura e se eximirem de sujar as mãos nos acordos necessários para manter uma nova ordem política e social, essa vertente prefere "se ater à Bela Alma". São grupos tão cheios de princípios que não possuem nenhum fim, tal como o PSOL brasileiro.

Portanto, longe de fazer uma apologia ao reivindicacionismo contemporâneo, um elogio dos momentos de explosão e de instabilidade, das faíscas da grande revolução, Žižek sabe reconhecer a histeria social que se insinua nessa posição, lembrando do quanto a histérica compõe a própria ordem da qual se queixa.

A crítica à esquerda revolucionária trata-se de uma crítica à própria esquerda marxista que, ao valorizar a metapolítica científica de Marx - a tese de que o que importa é a infraestrutura, as relações materiais de produção -, permite esquecer-se da decência e da ética básicas no trato com as pessoas, resultando em regimes totalitários como o stalinista.

Quanto à direita ultraconservadora, creio que a crítica fica evidente após comparada às militâncias de minorias identitárias - é uma questão de tomar seu próprio modo de existência como referência - em uma estrutura fundamentalista homóloga. Essa posição fundamentalista é, basicamente, a seguinte: uma defesa contra a política (como conflito) pela via da ultrapolítica, pela transformação da política em guerra ("Nós" contra "Eles"). É o que podemos ver emergir em regimes como o Nazi-fascismo.

Já a crítica ao liberalismo capitalista global, longe de repetir a mesma ferramenta marxista de sempre, é feita ao situá-lo como a negação mais radical da política. Equiparada ao mecanismo lacaniano de foraclusão, o autor conclui que a política, daí, passa longe. 
Isso se dá devido à pretensão do estabelecimento de um discurso, suposto, metapolítico, que os técnicos liberais perpetuam - economistas, especialistas da opinião, etc. Esse discurso se pretende fora da política, apolítico, neutro, objetivo, com a pretensão de valorizar as boas ideias, as ideias "que funcionam" - e as ideias que funcionam são aquelas que continuam gerando rentabilidade para o capitalismo financeiro global. Ou seja, é uma posição política feita para rechaçar a política como tal, que é o conflito.

Ao mostrar, portanto, que todas as grandes posições políticas que conhecemos são, basicamente, defesas contra a política, que posição este livro nos deixaria como não defensiva, ou seja, como aceitação da política? Seu subtítulo já anuncia que o centro da ontologia política é ausente, mas seria isso equivalente a dizer, como Lacan, que o mais subversivo de seu discurso é o fato de afirmar não possuir uma solução?

Pois bem, justamente, não! Žižek encontra na teoria psicanalítica soluções para esses impasses e aporias da filosofia política e avança um pouco além da era das grandes ideologias em um rumo muito inspirador. Esse rumo, entretanto, deixo em suspenso e os remeto ao texto, esperando que esta resenha tenha atiçado suficientemente a isca diante daqueles que estão causados pelas desventuras da política contemporânea e que, seguramente, verão exemplos atuais e vivos da política se desdobrarem a olhos vistos ao longo da leitura.

Está aí um sujeito incômodo que tem algo a dizer sobre o momento. Seguramente, quando se trata de política, Slavoj Žižek não é um amador!

Citacão/Citation: Silva Neto, E. A. (mai. a out. 2016). A Sociedade não existe! Revista aSEPHallus de Orientação Lacaniana, 11(22), 141-144. Disponível em www.isepol.com/asephallus. doi: 10.17852/1809709x.2019v11n22p141-144.

Editor do artigo: Tania Coelho dos Santos.

Recebido/Received: 24/10/2016 / 10/24/2016.

Aceito/Accepted: 28/10/2016 / 10/28/2016.

Copyright: (C) 2013 Associação Núcleo Sephora de Pesquisa sobre o moderno e o contemporâneo. Este é um artigo de livre acesso, que permite uso irrestrito, distribuição e reprodução em qualquer meio, desde que o autor e a fonte sejam citados/This is an open-access article, which permites unrestricted use, distribution, and reproduction in any medium, provided the author and source are credited. 